\title{
Metsänomistajien näkemykset energiapuukaupasta Etelä- ja Keski- Pohjanmaalla
}

\author{
Varpu Hulsi ${ }^{1)}$, Tuomas Hakonen ${ }^{1)}$, Risto Lauhanen ${ }^{1)}$ ja Jussi Laurila ${ }^{2)}$ \\ ${ }^{1)}$ SeAMK Elintarvike ja maatalous, Kalevankatu 35, 60100 Seinäjoki, varpu.hulsi@seamk.fi, \\ tuomas.hakonen@seamk.fi,risto.lauhanen@seamk.fi \\ ${ }^{2)}$ Suomen metsäkeskus, Julkiset palvelut, Huhtalantie 2, 60230 Seinäjoki, \\ jussi.laurila@metsakeskus.fi
}

\section{TIIVISTELMÄ}

Tutkimuksen tavoitteena oli selvittää energiapuun myyntihalukkuutta Suomen metsäkeskuksen Eteläja Keski-Pohjanmaan alueyksikön alueella. Lisäksi selvitettiin yksityismetsänomistajien kokemuksia energiapuukaupoista, mielipiteitä metsäenergian hinnoittelusta, energiapuun hankinnan hyviä ja huonoja puolia sekä metsänomistajien mielestä tärkeimpiä tekijöitä energiapuun hankinnan ja myynnin yhteydessä.

Tutkimus toteutettiin postikyselynä, ja 600 metsänomistajalle lähetettiin kirjeet marraskuussa 2012. Vastauksia saatiin 153 kappaletta, jolloin kyselyn vastausosuus oli 25,5\%.

Vastaajista 35,3 \% oli myynyt energiapuuta. Energiapuuta olivat tyypillisimmin tarjonneet enintään 50 hehtaaria metsää omistavat ja ammattiasemaltaan eläkeläiset. Kaikista vastaajista eläkeläiset olivat myös parhaiten edustettuina, ammattiasemakseen tämän oli valinnut runsas 35 \%.

Yleisin energiapuukaupan este oli oman polttopuun tarve. Toiseksi yleisin syy energiapuun myymättä jättämiselle oli ollut puun alhainen hinta. Ostajilta saatava energiapuun hintainformaatio koettiin epäselväksi.

Vain 38 \% energiapuuta myyneistä vastaajista oli hakenut jotakin nuoren metsän hoidon tai energiapuun korjuun tukimuotoa. Yleisin haettu tuki oli vastaajien mukaan energiapuun korjuutuki. Suurin osa vastaajista ei ollut hakenut mitään tukimuotoa. Vastaajat olivat osin epätietoisia haettavista tuista.

Valtaosa vastaajista oli sitä mieltä, että metsäenergia on varteenotettava vaihtoehto energiantuotannossa ja metsäenergian käytön yleistymisellä uskottiin olevan myös taloudellista merkitystä Eteläja Keski-Pohjanmaalle.

Yli puolet $(51,3 \%)$ vastaajista piti energiapuuerän tilavuuteen pohjautuvaa hinnoittelua $\left(€ / \mathrm{m}^{3}\right)$ parhaana hinnoitteluperusteena energiapuulle. Metsänhoitoyhdistysten lisäksi ammatti- ja päivälehdet olivat yleisiä metsänomistajien tietolähteitä. Lehtien lisäksi myös Internet on tärkeä tietolähde etenkin nuoremmille metsänomistajille.

Vastaajista 32,2 \% aikoi myydä energiapuuta tulevaisuudessa. Vaikka energiapuun myyntiin suhtauduttiin vielä varoen, vastaajien mielipiteet metsäenergiasta olivat varsin positiivisia. Ravinteiden poistuminen maaperästä hakkuutähteiden keruun ja kantojen noston yhteydessä koettiin kuitenkin negatiiviseksi seikaksi. Metsänhoito oli vastaajien kesken tärkein tekijä energiapuun hankinnan ja myynnin yhteydessä. Tutkimustulokset edustavat kyselyyn vastanneiden näkemyksiä energiapuukaupasta kyselyn toteutushetkellä.

\section{Asiasanat}

energiapuu, kyselytutkimus, metsänomistajat, puukauppa, raakapuumarkkinat, tukipolitiikat 


\section{Johdanto}

Vuonna 2011 lämpö- ja voimalaitokset käyttivät yhteensä yli 6,8 miljoonaa kuutiometriä metsähaketta. Lähes puolet metsähakkeesta valmistettiin pienpuusta eli karsitusta rangasta, karsimattomasta pienpuusta ja kuitupuusta. Hakkeen raaka-aineina käytettiin myös hakkuutähteitä, kantoja ja juurakoita sekä järeää runkopuuta. (Metinfo 2011.) Pientalot (omakotitalot, maatilat, vapaa-ajan asunnot) käyttivät yhteensä 6,7 miljoonaa kuutiometriä puuta lämmityskaudella 2007/2008. Metsähaketta käytetään lämpö- ja voimalaitosten lisäksi myös pientaloissa, pääasiassa maatiloilla. Lämmityskaudella 2007/2008 pientalojen metsähakkeen kulutus oli 0,7 miljoonaa kuutiometriä. (Torvelainen 2009.)

Metsänomistaja 2010 - tutkimuksen (Hänninen ym. 2011) mukaan vuosina 2004 - 2008 aikana energiapuuta oli omatoimisesti korjattu joka neljännellä tilalla. Energiapuun korjuuseen ja haketukseen tukea oli saanut joka kahdeskymmenes metsänomistaja. Tutkimukseen osallistuneista joka kuudes metsänomistaja oli myynyt energiajakeita metsästään ja näistä runsas neljäsosa oli myynyt ne ainespuukaupan yhteydessä. Energiapuukauppa oli tavallisimmin tehty uudistusalueen hakkuutähteistä ja toiseksi yleisimmin harvennusmetsien energiarangasta. Energiajakeista selvästi vähiten oli myyty kantoja, vain alle kymmenesosa puukaupan tehneistä.

Tutkimushetkellä tekeillä ollut, mm. metsänomistajien energiapuun myyntihalukkuutta koskenut pro gradu - työ esiteltiin Stora Enson asiakaslehdessä (Lisää... 2012). Kansallisella tasolla metsänomistajien energiapuumyyntejä ja -myyntihalukkuutta ovat aiemmin tutkineet mm. Rämö ym. (2001) sekä Järvinen ym. (2006). Energiapuumarkkinoita ovat tutkineet viimeksi Anttila ym. (2012). Suomen raakapuumarkkinat ovat yksityismetsien varassa. Energiapuukauppaan liittyvät käytännöt ja toimintatavat ovat olleet suurelta osin vakiintumattomia. Metsäenergian tuotannon ja käytön kasvuodotusten saavuttamiseksi myös yksityismetsänomistajien aktiivisuutta energiapuun myyntiin on lisättävä. Jotta metsänomistajat saataisiin aktivoitumaan, on tärkeää selvittää metsänomistajien puunmyyntipäätökseen vaikuttavia tekijöitä.

Tämän tutkimuksen tavoitteena on tuottaa tietoa Etelä- ja Keski-Pohjanmaan metsäkeskusalueen metsänomistajien energiapuun myyntihalukkuudesta. Tutkimuksessa selvitetään metsänomistajien taustatietoja, energiapuunmyyntihistoriaa, mahdollisia tulevia energiapuukauppoja sekä mielipiteitä metsäenergiaan liittyen.

Tutkimus tehtiin EU:n ja valtion sekä Etelä- ja Keski-Pohjanmaan alueen yksityisten metsäenergiatoimijoiden rahoittamassa Kestävä metsäenergia -hankkeessa osana Manner-Suomen maaseutuohjelmaa. Tutkimus on julkaistu kokonaisuudessaan Internetissä Seinäjoen ammattikorkeakoulun julkaisusarjassa B. Raportteja ja selvityksiä 71.

\section{Aineisto ja menetelmät}

Tutkimuksen perusjoukon muodostivat Suomen metsäkeskuksen Etelä- ja Keski-Pohjanmaan alueyksikön toimialueella vähintään 10 hehtaarin kokoiset yksityiset metsätilat ilman kuolinpesiä ja perikuntia. Aineisto saatiin Suomen metsäkeskuksen tietokannasta. Perusjoukon kooksi muodostui valituilla ehdoilla noin 25600 metsätilaa. Perusjoukosta poimittiin 600 metsätilan otos, joille postikysely lähetettiin marraskuussa 2012. Kyselyn vastausprosentiksi tuli 27,5. Lomakkeista jouduttiin kuitenkin hylkäämään 12 kappaletta puuttuvien vastauksien vuoksi, joten lopulliseksi vastausprosentiksi muodostui 25,5.

Kyselylomakkeella taustatietoina olivat metsänomistajan sukupuoli, ikä, koulutustausta, ammattiasema, perustiedot omistuksessa olevasta metsätilasta sekä ensisijaiset tavoitteet metsänomistukselle. Metsänomistajien taustatietojen avulla pyrittiin selvittämään taustatekijöiden mahdolliset vaikutukset energiapuun myyntihistoriaan, energiapuukauppoihin ja metsäenergiatietoisuuteen.

Vastaukset koottiin MS Excel 2010 - taulukkolaskentaohjelmalla havaintomatriisiksi. Khiinneliötestin avulla selvitettiin sukupuolen, iän ja metsätaloussuunnitelman voimassaolon vaikutusta energiapuun myyntihistoriaan ja tulevaisuuden myyntihalukkuuteen nähden.

Vastauksien käsittelyssä meneteltiin niin, ettei kenenkään vastaajan yksityisyyttä vaarannettu eli yksittäinen vastaus ei ole erotettavissa tunnistettavassa muodossa. 


\section{Tulokset ja tarkastelu}

Etelä- ja Keski-Pohjanmaan metsistä voitaisiin korjata arviolta 0,8 miljoonaa kuutiota energiapuuta vuosittain (Laurila ym. 2010.) Vastaajista noin 35 \% oli tarjonnut energiapuuta myytäväksi, kuitenkin valtaosa tutkimukseen osallistuneista ei ollut myynyt energiapuuta aiemmin. Tuloksia tarkasteltaessa on huomattava, että vastaukset edustavat kyselyyn vastanneiden näkemyksiä energiapuusektorista kyselyn toteutushetkellä. Kyselyn vastausosuus oli 25,5 \%, mitä voidaan pitää edustavana ja kyselytutkimukselle tyypillisenä.

Enin osa vastaajista (62,7 \%) ei ollut myynyt energiapuuta ja 2 \% ei osannut sanoa, oliko heidän metsästään korjattu energiapuuta myytäväksi vai ei. Viime vuosien energiapuun käytön kasvu näkyy kyselyn tuloksissa, sillä energiapuuta myyneistä vastaajista 88,9 \% oli myynyt energiapuuta viimeisen 5 -vuoden aikana. Vastausten perusteella energiapuukaupan keskikoko oli $165,7 \mathrm{~m}^{3}$ vaihteluvälin ollessa $10 \mathrm{~m}^{3}-1000 \mathrm{~m}^{3}$.

Tyypillisimmin energiapuuta olivat myyneet miespuoliset, peruskoulutukseltaan ammattikoulun käyneet metsänomistajat, 56 - 65-vuotiaat metsänomistajat, eläkeläiset sekä enintään 50 hehtaaria metsää omistavat.

Iällä tai sukupuolella ei ollut vaikutusta energiapuun myyntiin tai myyntiaikeisiin. Ajantasaisen metsätaloussuunnitelman ja myyntiaikeiden välillä oli riippuvuutta Khiin-neliötestin perusteella $\left(\mathrm{p}<0,013^{*}\right)$. Vaikka metsätaloussuunnitelma oli suurimmalla osalla kyselyyn osallistuneista, voidaan silti olettaa, että metsätaloussuunnitelma on kannustanut energiapuun myyntiaikaisiin.

Kaikista vastaajista eläkeläiset (35 \%) olivat parhaiten edustettuina. Myös yksityismetsänomistajien energiapuun tarjonta ja suhtautuminen puun energiakäyttöön (Rämö ym. 2001) -tutkimuksessa eläkeläisten ryhmä oli suurin (35 \%). Koska eläkeläisten osuus oli merkittävä, tulisi eläkeläismetsänomistajia sekä mahdollisen sukupolvenvaihdoksen edessä olevia metsänomistajia informoida ja kannustaa energiapuun myyntiin. Jotta metsänomistajat myisivät energiapuuta, tulisi kysynnän olla riittävää. Lisäksi energiapuun ostajista sekä hinnoista pitäisi olla tietoa nykyistä helpommin saatavilla.

Yleisin energiapuukaupoissa käytetty puukauppamuoto oli pystykauppa. Energiapuuta myyneistä vastaajista 54,7 \% oli myynyt puunsa pystykaupalla, 34,0 \% hankintakaupalla ja 11,3 \% käteiskaupalla.

Energiapuuta myyneistä vastaajista $38 \%$ oli hakenut jotakin tukimuotoa. Tukia hakeneista suurin osa (36,8 \%) ilmoitti hakeneensa energiapuun korjuutukea, toiseksi eniten oli haettu pinta-alatukea (15,8 \%) sekä korjuu- ja pinta-alatukea yhdessä (15,8 \%). Valtaosa energiapuuta myyneistä vastaajista (62 $\%)$ ei ollut hakenut mitään tukimuotoa. Näin ollen vastaajat olivat huonosti selvillä energiapuun hankintaan saatavista tuista ja alan säädöksistä.

Kyselyyn vastanneista $62,7 \%$ ei ollut myynyt energiapuuta. Näistä vastaajista 28,6 \% oli valinnut merkittävimmäksi esteeksi energiapuun myymiselle vaihtoehdon "Muu”. Tässä kohdassa enin osa eli 57,7 \% kohdan valinneista oli maininnut oman polttopuun tarpeen esteeksi. Erityisesti broileri- ja sikatiloilla tarvitaan oman metsän puuta hakelämmityksessä. Tulevaisuudessa metsänomistajien oman puun käyttö tulee vähintäänkin säilymään nykytasolla.

Kaupan esteeksi oli mainittu myös myyntihaluttomuus, sopivien myyntikohteiden puuttuminen sekä korjuukustannusten kalleus. Taimikonhoidon onnistuminen poisti myös nuoren metsän hoitotarpeen ja energiapuukauppatarpeen (Kuvio 1). 


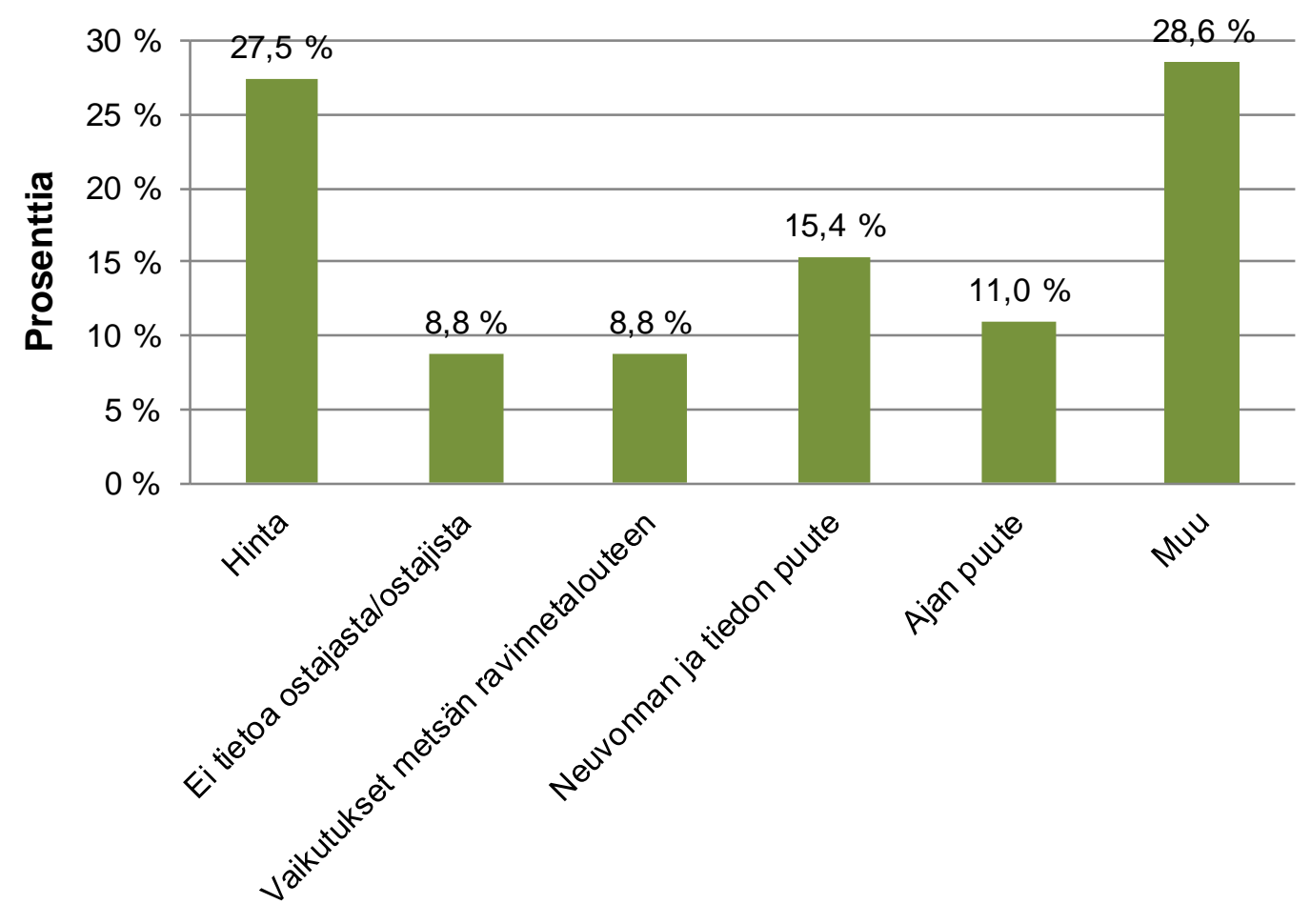

Kuvio 1. Vastaajien merkittävimmät esteet energiapuun myymiselle $(\mathbf{n}=91)$

Toiseksi yleisin syy myymättä jättämiselle oli oletetusti ollut energiapuun alhainen hinta (27,5 \% vastaajista) (Kuvio 1).

Vastaajista 32,2 \% aikoo myydä jatkossa energiapuuta. Sen sijaan 30,3 \% ei aio myydä energiapuuta lähitulevaisuudessa. Vastaajista enemmistö (37,5 \%) ei osannut sanoa lähitulevaisuuden energiapuukaupoistaan. Energiapuun hinta-asioissa ilmeni epäselvyyttä. Energiapuun moninaisilla hinnoittelutavoilla - ja perusteilla sekä meneillään olevalla energiapuun tukien uudistuksella on saattanut olla vaikutusta vastaajien mielipiteeseen. Vastaajat, jotka eivät aikoneet myydä energiapuuta tulevaisuudessa, olivat hyvin samankaltainen ryhmä myyneiden kanssa.

Vastaajat olivat varsin yksimielisiä väittämän "Metsäenergia on varteenotettava vaihtoehto energiantuotannossa” kohdalla. Vastaajista 89,5 \% oli joko täysin samaa mieltä tai osin samaa mieltä väittämän kanssa. Vastaajista 86,7 \% oli joko täysin samaa mieltä tai osin samaa mieltä väittämän "Metsäenergian käytön yleistymisellä on Etelä- ja Keski-Pohjanmaalle taloudellista merkitystä” kohdalla. Väittämän "Metsäenergian hyödyntäminen lisää toimeentulomahdollisuuksia hajaasutusalueilla” kanssa 89,5 \% vastaajista oli joko täysin samaa mieltä tai osin samaa mieltä väittämän kanssa.

Vastaajista 51,3 \% oli sitä mieltä, että energiapuu olisi paras hinnoitella sen kiintotilavuuden mukaan $\left(€ / \mathrm{m}^{3}\right)$. Toiseksi eniten kannatusta sai hinnoittelu puun sisältämän energiasisällön mukaan (€/MWh). Pinta-alaperuste ( $€ /$ ha) sai vastaajien kesken kovin vähän kannatusta. Noin $5 \%$ vastaajista hinnoitteluperusteella ei ollut väliä. Noin kymmenesosa vastaajista ei osannut sanoa, mikä olisi paras hinnoitteluperuste.

Vastaajilta kysyttiin eri energiapuumuotojen positiivisia ja negatiivisia puolia sekä negatiivisten puolien mahdollista vaikutusta energiapuun myyntiin. Yleisimmin mainittu positiivinen puoli oli metsän uudistusalan siisteys sekä helppo uudistettavuus hakkuutähteiden keruun jälkeen. Tämän vastauksen oli maininnut $27,7 \%$ vastaajista.

Vastaajien mielestä toiseksi yleisin positiivinen puoli liittyi energiapuunkorjuuseen yleisellä tasolla, eikä niinkään yksittäiseen energiapuumuotoon. Vastaajista 25,7 \% oli sitä mieltä, että energiapuun keruu on hyvä metsänhoidollinen toimenpide. Muita mainittuja positiivisia puolia olivat mm. 
"metsäenergian työllistävä vaikutus, uusiutuva kotimainen luonnonvara, hyvä energian lähde sekä lisätulot metsänomistajalle.”

Negatiivisia puolia oli mainittu enemmän. Vastaajista 57,4 \% oli maininnut ravinteiden vähenemisen, häviämisen sekä huuhtoutumisen etenkin hakkuutähteiden keruun ja kantojen noston yhteydessä. Ravinteiden vähenemiseen liitettiin yleisesti myös pieneliöiden häviäminen. Negatiiviseksi oli mielletty myös kannot energiapuumuotona sekä kantojen nosto.

\section{Johtopäätökset}

Tulokset edustavat kyselyyn vastanneiden näkemyksiä energiapuusektorista kyselyn toteutushetkellä. Vastaajista noin 35 \% oli tarjonnut energiapuuta myytäväksi, kuitenkin valtaosa tutkimukseen osallistuneista (62,7 \%) ei ollut myynyt energiapuuta aikaisemmin.

Vastaajien enemmistö (37,5 \%) ei osannut sanoa lähitulevaisuuden energiapuukaupoistaan. Tämä osoittaa, että energiapuukaupassa, hinnoittelussa sekä energiapuun tukiasioissa ilmeni epätietoisuutta. Näin ollen metsänomistajien neuvontaa tarvitaan energiapuuasioissa.

Vaikka energiapuun myyntiin suhtauduttiin vielä varoen, vastaajien mielipiteet metsäenergiasta olivat varsin positiivisia. Ravinteiden poistuminen maaperästä hakkuutähteiden keruun ja kantojen noston yhteydessä koettiin kuitenkin negatiiviseksi seikaksi.

\section{Lähteet}

Anttila, P., Kurki, P. \& Mutanen, A. 2012. Energiapuumarkkinat - käytännön kokemukset ja tilastointimahdollisuudet. Metsäntutkimuslaitoksen työraportteja 228. [Verkkojulkaisu]. Vantaa: Metsäntutkimuslaitos. [Viitattu 28.11.2012]. Saatavana: http://www.metla.fi/julkaisut/workingpapers/2012/mwp228.htm

Hänninen, H., Karppinen, H. \& Leppänen, J. 2011. Suomalainen metsänomistaja 2010. Metsäntutkimuslaitoksen työraportteja 208. [Verkkojulkaisu]. Vantaa: Metsäntutkimuslaitos. [Viitattu 23.11.2012]. Saatavana: http://www.metla.fi/julkaisut/workingpapers/2011/mwp208.htm

Järvinen, E., Rämö, A-K. \& Silvennoinen, H. 2006. Pellervon taloudellisen tutkimuslaitoksen raportteja N:o 199: Energiapuun tuotanto ja markkinat: Metsänomistajakysely. Helsinki: Pellervon taloudellinen tutkimuslaitos PTT.

Laurila, J., Tasanen, T. \& Lauhanen, R. 2010. Metsäenergiapotentiaali ja energiapuun korjuun resurssitarpeet Etelä-Pohjanmaan metsäkeskuksen alueella. Metsätieteen aikakauskirja 4/2010: 355-365.

Lisää energiaa metsästä. 2012. Terve Metsä 04/2012, 5.

Metinfo. Tilastopalvelu. 2011. Puun käyttö. [Verkkosivu]. [Viitattu 13.11.2012]. Saatavana: http://www.metla.fi/metinfo/tilasto/puunkaytto/

Rämö, A-K., Tahvanainen, L. \& Toivonen, R. 2001. Pellervon taloudellisen tutkimuslaitoksen raportteja N:o 175: Yksityismetsänomistajien energiapuun tarjonta ja suhtautuminen puun energiakäyttöön. Helsinki: Pellervon taloudellinen tutkimuslaitos PTT.

Torvelainen, J. 2009. Metsätilastotiedote 26/2009: Pientalojen polttopuunkäyttö 2007/2008. [Verkkojulkaisu]. Vantaa: Metsäntutkimuslaitos. [Viitattu: 13.11.2012]. Saatavana: www.metla.fi/metinfo/tilasto/julkaisut/mtt/2009/pientalopolttopuu2008.pdf 